\title{
Criptógamos do Parque Estadual das Fontes do Ipiranga, São Paulo, SP. Pteridophyta: 21. Tectariaceae
}

\author{
Jefferson Prado ${ }^{1,3}$ e Regina Yoshie Hirai ${ }^{2}$
}

Recebido: 03.09.2009; aceito: 04.06.2010

ABSTRACT - (Cryptogams of "Parque Estadual das Fontes do Ipiranga", São Paulo, SP. Pteridophyta: 21. Tectariaceae). In this paper are presented the data of the floristic survey of the family Tectariaceae in the "Parque Estadual das Fontes do Ipiranga (PEFI)". The family is represented in the area by three genera (Ctenitis, Lastreopsis, and Megalastrum) and seven species: three of Ctenitis (C. aspidioides (C. Presl) Copel., C. distans (Brack) Ching, and C. falciculata (Raddi) Ching), one of Lastreopsis (L. amplissima (C. Presl) Tindale), and three of Megalastrum (M. albidum R.C. Moran et al., M. connexum (Kaulf.) A.R. Sm. \& R.C. Moran, and M. crenulans (Fée) A.R. Sm. \& R.C. Moran). Identification keys for genera and species, as well as descriptions, geographical distribution, comments, and illustrations for some studied taxa are presented. Key words: Ctenitis, Dryopteridaceae, Lastreopsis, Megalastrum

RESUMO - (Criptógamos do Parque Estadual das Fontes do Ipiranga, São Paulo, SP. Pteridophyta: 21. Tectariaceae). Neste trabalho são apresentados os dados referentes ao levantamento florístico da família Tectariaceae no Parque Estadual das Fontes do Ipiranga (PEFI) que está representada na área por três gêneros (Ctenitis, Lastreopsis e Megalastrum) e sete espécies: três de Ctenitis (C. aspidioides (C. Presl) Copel., C. distans (Brack) Ching e C. falciculata (Raddi) Ching), uma de Lastreopsis (L. amplissima (C. Presl) Tindale) e três de Megalastrum (M. albidum R.C. Moran et al., M. connexum (Kaulf.) A.R. Sm. \& R.C. Moran e M. crenulans (Fée) A.R. Sm. \& R.C. Moran). São apresentadas chaves para identificação dos gêneros e espécies, bem como descrições, distribuição geográfica, comentários e ilustrações para alguns dos táxons estudados.

Palavras-chave: Ctenitis, Dryopteridaceae, Lastreopsis, Megalastrum

\section{Introdução}

O presente estudo é parte do levantamento florístico das samambaias e licófitas do Parque Estadual das Fontes do Ipiranga (PEFI).

No primeiro trabalho realizado por Hoehne et al. (1941), para a área do Parque e que envolveu esse grupo (Tectariaceae), foram registradas apenas duas espécies: uma delas era procedente dos arredores da capital, sendo posteriormente cultivada nas estufas da área de visitação ("Dryopteris amplissima (C. Presl) Kuntze") e a outra espécie foi citada como nativa do Jardim Botânico ("Dryopteris laetevirens Rosenst.").
Os principais estudos taxonômicos com esse grupo, em especial com os gêneros encontrados no PEFI, foram os trabalhos realizados por Christensen (1913) com Dryopteris, Tindale (1965) com Lastreopsis e mais recentemente por Moran et al. (2009) com Megalastrum. Esses três trabalhos apresentam a monografia para os respectivos gêneros e contemplam de modo geral as espécies brasileiras.

Com exceção desse último trabalho de revisão de Megalastrum do Brasil (incluindo Paraguai e Uruguai), não existe nenhum trabalho específico com o grupo, apenas um trabalho de Salino \& Morais (2003) de combinação nova, para duas espécies de Ctenitis

1. Instituto de Botânica, Herbário SP, Caixa Postal 3005, 01031-970 São Paulo, SP, Brasil

2. Curso de Pós-Graduação em Biodiversidade Vegetal e Meio Ambiente, Instituto de Botânica, Caixa Postal 3005, 01031-970, São Paulo, SP, Brasil

3. Autor para correspondência:.jprado.01@uol.com.br 
do Brasil: C. abyssi (Sehnem) Salino \& P.O. Morais e C. laetevirens (Rosenst.) Salino \& P.O. Morais, e algumas floras regionais nas quais aparecem esses gêneros, como por exemplo, Boldrin \& Prado (2007) para o estado de São Paulo, no qual foram tratados três gêneros e quatro espécies de Tectariaceae.

O objetivo principal do presente trabalho foi complementar e atualizar o inventário das samambaias e licófitas do PEFI iniciado por Hoehne et al. (1941).

\section{Material e métodos}

O material foi coletado de acordo com as técnicas descritas em Fidalgo \& Bononi (1984) e encontrase depositado no Herbário do Instituto de Botânica (SP) e no Herbário do Departamento de Botânica da Universidade de São Paulo (SPF).

Os dados sobre a caracterização e localização do Parque Estadual das Fontes do Ipiranga (PEFI), bem como o planejamento desta flora, foram apresentados em Melhem et al. (1981) e Milanez et al. (1990).

Segundo a classificação de Smith et al. (2006, 2008), baseada em filogenia molecular, os gêneros Ctenitis, Lastreopsis e Megalastrum encontram-se atualmente na família Dryopteridaceae. No entanto, como esta flora do PEFI foi iniciada em 2004 adotando a circunscrição de famílias utilizada por Moran \& Riba (1995), para a Flora Mesoamericana, foi mantido essa mesma circunscrição no presente trabalho. A descrição de Tectariaceae, então, segue o conceito de Moran (1995).

Foram utilizadas na descrição das espécies (Ctenitis, Lastreopsis e Megalastrum) o mesmo conceito utilizado por Moran et al. (2009) para as escamas unisseriadas ("proscales"), filiformes, geralmente adpressas e castanho-avermelhadas.

$\mathrm{O}$ número que antecede o nome da família, no título deste trabalho, corresponde à numeração das famílias apresentadas em Prado (2004). A chave para as famílias, incluindo Tectariaceae, também foi publicada por Prado (2004).

Os táxons estudados estão apresentados em ordem alfabética de gêneros e espécies.
A abreviação dos nomes dos autores de táxons está de acordo com Pichi-Sermolli (1996).

Foram feitas apenas ilustrações das espécies de Ctenitis, uma vez que no recente estudo de Moran et al. (2009), com Megalastrum, todas as espécies deste gênero que foram encontradas no PEFI aparecem ilustradas. Lastreopsis amplissima é uma espécie de fácil identificação e optou-se por não ilustrá-la.

\section{Resultados e Discussão}

No primeiro trabalho realizado por Hoehne et al. (1941), para a área do Parque e que envolveu as samambaias, foram registradas apenas duas espécies de Tectariaceae: "Dryopteris amplissima (C. Presl) Kuntze" e "Dryopteris laetevirens Rosenst.".

No presente levantamento foram encontradas na área do PEFI sete espécies nesse grupo, distribuídas em três gêneros: Ctenitis, Lastreopsis e Megalastrum.

Tectariaceae

Plantas terrestes ou rupícolas. Rizoma com escamas. Frondes contínuas com o rizoma (não articuladas), monomorfas ou dimorfas; base do pecíolo com mais de três feixes vasculares, com escamas; pinas contínuas com a raque (não articuladas); raque, costa e cóstula adaxialmente arredondadas, não sulcadas ou inconspicuamente sulcadas, pubescentes, tricomas geralmente eretos a patentes, catenados ou, em Megalastrum, aciculares, esbranquiçados, antrorsamente estrigosos a patentes. Soros geralmente arredondados; indúsio presente ou raramente ausente; pedicelo dos esporângios com três fileiras de células; ânulo vertical, interrompido pelo pedicelo; esporos monoletes, aclorofilados.

Segundo Moran (1995), é uma família cosmopolita que geralmente ocorre nas regiões tropicais, possui 15 gêneros e aproximadamente 500 espécies.

Atualmente com a nova circunscrição das famílias de samambaias, baseada em filogenia molecular, Ctenitis, Lastreopsis e Megalastrum pertencem a outra família denominada Dryopteridaceae, que como definido por Smith et al. (2006, 2008), apresenta cerca de 40-45 gêneros e 1.700 espécies.

Chave para os gêneros de Tectariaceae

1. Tricomas aciculares presentes na face adaxial da raque e raquíola; ápice das nervuras claviforme; nervura proximal do lado basiscópico das pínulas distais originando-se da raquíola Megalastrum 
1. Tricomas catenados ou clavados presentes na face adaxial da raque e raquíola; ápice das nervuras não claviforme; nervura proximal do lado basiscópico das pínulas distais originando-se da cóstula

2. Raque e raquíola adaxialmente com tricomas catenados; raque sem bordas proeminentes na face adaxial Ctenitis

2. Raque e raquíola adaxialmente com tricomas clavados; raque com duas bordas proeminentes na face adaxial, contínuas com a raquíola e costa

Lastreopsis

Ctenitis (C. Chr.) C. Chr.

Plantas terrestres ou, mais raramente, rupícolas. Rizoma ereto ou levemente ascendente ou, às vezes, curto-reptante, com escamas. Lâmina 1-4-pinadopinatífida, catadrômica, cartácea, raramente coriácea, raque sem bordas proeminentes na face adaxial, costa sem ala; indumento formado por tricomas catenados e glandulares; raque, raquíola e costa revestidas no lado adaxial por escamas com margens geralmente denteadas, raramente inteiras ou ciliadas, muitas vezes clatradas, tricomas catenados, castanho-avermelhados, articulados, com células adjacentes colapsadas em ângulos retos uma em relação à outra, geralmente com paredes transversais das células espessadas visíveis; nervuras em ambas as superfícies laminares visíveis, livres, simples, raramente furcadas, com ápice delgado (não claviforme), terminando geralmente antes das margens da lâmina, nervura proximal do lado basiscópico das pínulas distais originando-se da cóstula. Soros arredondados, com ou sem indúsio, indúsio quando presente reniforme, raramente persistente; esporângios com tricomas glandulares no pedicelo ou tricomas ausentes.

É um gênero com aproximadamente 150 espécies, distribuídas nos trópicos, entre o Velho e o Novo Mundo, ocorrendo geralmente em regiões de baixa a média altitude (Mickel \& Smith 2004a).

\section{Chave para as espécies de Ctenitis}

1. Tecido laminar entre as nervuras abaxialmente com tricomas glandulares C. distans

1. Tecido laminar entre as nervuras abaxialmente sem tricomas glandulares

2. Pina apical conforme (igual na forma às pinas laterais) e geralmente conspícua; tricomas catenados com 0,1-0,2 mm compr. sobre a costa adaxialmente e com 0,05-0,10 mm compr. nas margens da lâmina ....

2. Ápice da lâmina profundamente pinatífido; tricomas catenados com 0,3-0,4 mm compr. sobre a costa adaxialmente e com 0,15-0,30 mm compr. nas margens da lâmina C. falciculata

Ctenitis aspidioides (C. Presl) Copel., Gen. Fil. 124. 1947 三 Polypodium aspidioides C. Presl, Del. Prag. 1: 170. 1822.

\section{Figuras 1A-E}

Frondes 35-120 cm compr.; escamas da base do pecíolo $6,0-8,0 \times 0,2-2,0 \mathrm{~mm}$, lineares a lanceoladas, margens inteiras ou esparsamente a irregularmente denticuladas, castanho-claras a castanho-escuras, não formando um tufo denso; lâmina $19-57 \mathrm{~cm}$ compr., 1-pinado-pinatífida (às vezes profundamente pinatífida); pinas pecioluladas, peciólulo 0,3-0,5 cm compr., pinatífidas a profundamente pinatífidas, incisões variando de $1 / 2$ a $2 / 3$ da distância entre a margem e a costa; pina proximal $8-12 \mathrm{~cm}$ compr.; pina apical conforme (igual na forma às pinas laterais) e geralmente conspícua; costa e cóstula abaxialmente sem tricomas, com escamas esparsas, 0,05-0,10 $\times$ 1,0-1,8 mm, não buladas, lineares e com margens esparsamente denticuladas, castanho-escuras a negras e com escamas unisseriadas, filiformes, adpressas, ca. 0,1 mm compr., castanho-avermelhadas; costa adaxialmente com tricomas 0,1-0,2 mm compr., catenados, sem tricomas glandulares e escamas; cóstula em geral adaxialmente sem tricomas, às vezes com tricomas catenados esparsos e com escamas unisseriadas semelhantes às da face abaxial; tecido laminar entre as nervuras abaxialmente e adaxialmente sem tricomas ou raramente com tricomas catenados esparsos, com escamas unisseriadas esparsas; nervuras visíveis em ambas as superfícies laminares, terminando próximo às margens, 6-9(-12) pares por segmento, simples, abaxialmente sem tricomas ou 
com tricomas catenados esparsos e com escamas unisseriadas, adaxialmente sem tricomas ou com tricomas catenados esparsos, sem escamas; margens da lâmina com tricomas, 0,05-0,10 mm compr., catenados; indúsio presente, com tricomas catenados nas margens.

Material examinado: 26-VI-1936, F.C. Hoehne s.n. (SP35630); 10-VIII-1948, W. Hoehne 2647 (SPF); 4-XI-1971, O. Handro 2179 (SPF); 2-VI-1972, O. Handro 2208 (SPF); 30-IV-1974, J.A. Corrêa 15 (SP); 2-VI-1976, J.A. Corrêa 137; 6-X-2003 (SP), J. Prado \& D.M. Vital 1442 (SP); 20-XII-2005, J. Prado \& G.B. Silva 1617 (SP).

Distribuição geográfica: endêmica das regiões sudeste e sul do Brasil (Rio de Janeiro, São Paulo, Paraná e Santa Catarina).

Ctenitis aspidioides pode ser reconhecida pela pina apical conforme, geralmente conspícua, pela presença de indúsio e lâmina com tricomas catenados nas margens. A espécie mais semelhante encontrada no PEFI é $C$. falciculata, mas difere pelas características utilizadas na chave.

Christensen (1913) tratou Ctenitis aspidioides como "Dryopteris alsophilacea (Kunze) Kuntze". Rosenstock (1915) mencionou que "Dryopteris laetevirens Rosenst." (= Ctenitis laetevirens (Rosenst.) Salino \& P.O. Morais) assemelha-se com C. aspidioides pela base da pina cuneada, soros com indúsio e frondes castanhas quando secas. Segundo Salino \& Morais (2003), C. laetevirens é reconhecida por não possuir tricomas catenados abaxialmente na costa, cóstula, nervuras e tecido laminar e as pinas são longo-pecioluladas como em C. aspidioides, no entanto o indúsio é ausente.

Dentre os espécimes estudados, foram observadas algumas pequenas variações morfológicas tais como: em Prado \& Silva 1617 observa-se que as nervuras da base das pinas não chegam até o sinus; em Handro 2208 o indúsio é de difícil visualização (aparentemente ausente) devido ao alto grau de maturação dos esporângios. Apesar dessas variações morfológicas observadas os espécimes apresentam todas as outras características diagnósticas da espécie.

Algumas vezes as escamas unisseriadas ("proscales") adpressas ao tecido laminar em Ctenitis podem ser confundidas com tricomas catenados.

Ctenitis distans (Brack) Ching, Bull. Mem. Inst. Biol. Bot. 8: 277. 1938 三Lastrea distans Brack., Expl. Exped. 16: 192. 1854.

Figuras 1F-J
Frondes ca. 1,8 m compr.; escamas da base do pecíolo $0,8-1,5 \times 0,1-0,5 \mathrm{~mm}$, lineares, margens inteiras, raramente denticuladas, castanho-claras a amareladas, formando um tufo denso; lâmina ca. 62 cm compr., 1-pinado-pinatissecta; pinas pecioluladas, peciólulo ca. $0,3 \mathrm{~cm}$ compr., pinatissectas, incisões $>$ $2 / 3$ da distância entre a margem e a costa; pina proximal ca. 14 cm compr.; ápice da lâmina pinatissecto; costa e cóstula abaxialmente com tricomas $0,2-0,3 \mathrm{~mm}$ compr., catenados, tricomas glandulares esparsos ou ausentes, com escamas 1,5-2,2 × 0,1-0,4 mm compr., não buladas, oval-lanceoladas, às vezes filiformes, margens denticuladas, castanho-claras a castanho-escuras, às vezes negras, adaxialmente com tricomas 0,3-0,4 mm compr., catenados, sem tricomas glandulares e escamas; tecido laminar entre as nervuras abaxialmente sem tricomas catenados, com tricomas glandulares e escamas unisseriadas esparsas, filiformes, adpressas, ca. 0,1 mm compr., castanho-avermelhadas, adaxialmente com tricomas 0,1-0,2 mm compr., catenados, sem tricomas glandulares e com escamas unisseriadas esparsas semelhantes às da face abaxial; nervuras visíveis em ambas as superfícies laminares, terminando próximo às margens, 10-12 pares por segmento, simples, abaxialmente com tricomas 0,10-0,15 $\mathrm{mm}$ compr., catenados, às vezes esparsos, sem tricomas glandulares, com escamas unisseriadas esparsas, adaxialmente com tricomas $0,1-0,3 \mathrm{~mm}$ compr., catenados, às vezes esparsos, sem tricomas glandulares e escamas; margens da lâmina com tricomas, 0,1-0,2 $\mathrm{mm}$ compr., catenados; indúsio presente, com tricomas catenados nas margens.

Material examinado: 13-VII-1960, G. Eiten \& L.T. Eiten 2080 (SP); 7-XI-1972, O. Handro 2213 (SP, SPF, MBM).

Distribuição geográfica: endêmica do Brasil (Bahia, Minas Gerais, Rio de Janeiro, São Paulo e Paraná).

É caracterizada por apresentar pinas com incisões maiores do que $2 / 3$ da distância entre a margem e a costa; escamas da costa não buladas, geralmente castanho-escuras, oval-lanceoladas, com margens denticuladas; tecido laminar entre as nervuras abaxialmente com tricomas glandulares; indúsio persistente.

Essa espécie foi tratada por Christensen (1913) como "Dryopteris ctenitis (Link) Kuntze" e na sua chave ela entrou na alternativa contendo lâmina sem tricomas glandulares. No entanto, nos comentários desta espécie, o autor comenta que a lâmina geralmente possui tricomas glandulares abaxialmente. Segundo 
esse mesmo autor, essa espécie é intermediária entre Ctenitis falciculata (Raddi) Ching e C. submarginalis (Langsd. \& Fisch.) Ching mas pode ser separada da primeira por apresentar menor número de nervuras (510 pares) por segmento e as escamas da costa ovais, e da segunda por possuir escamas da raque amareladas a avermelhadas e indúsio geralmente ausente.

Ctenitis falciculata (Raddi) Ching, Sunyatsenia 5: 250. $1940 \equiv$ Aspidium falciculatum Raddi, Opusc. sci. Bol. 3: 289. 1819.

Figuras $1 \mathrm{~K}-\mathrm{O}$

Frondes 41-55 cm compr.; escamas da base do pecíolo não observadas; lâmina $29-33 \mathrm{~cm}$ compr.; 1-pinado-pinatífida (profundamente pinatífida); pinas pecioluladas, peciólulo 0,2-2,5 $\mathrm{mm}$ compr., profundamente pinatífidas, incisões com $2 / 3$ da distância entre a margem e a costa, pina proximal 8,5-10,0 cm compr.; ápice da lâmina profundamente pinatífido; costa abaxialmente sem tricomas catenados ou estes raramente esparsos, sem tricomas glandulares, com escamas 1,1-1,5 × 0,10$0,15 \mathrm{~mm}$ compr., não buladas, lanceoladas, às vezes filiformes, margens denticuladas, castanho-claras a castanho-escuras, adaxialmente com tricomas 0,30,4 mm compr., catenados, sem tricomas glandulares e escamas; cóstula abaxialmente com tricomas esparsos, 0,1-0,3 mm compr., catenados, sem tricomas glandulares e escamas, adaxialmente com tricomas 0,3-0,4 mm compr., catenados, sem tricomas glandulares e escamas; tecido laminar entre as nervuras abaxialmente e adaxialmente sem tricomas, ou raramente com tricomas catenados esparsos, sem escamas; nervuras visíveis em ambas as superfícies laminares, terminando próximo às margens, 5-8 pares por segmento, simples, adaxialmente com tricomas esparsos, 0,2-0,3 mm compr., catenados, sem tricomas glandulares e escamas, abaxialmente com tricomas esparsos, 0,2-0,3 mm compr., catenados, escamas unisseriadas esparsas, filiformes, adpressas, ca. 0,1 mm compr., castanho-avermelhadas; margens da lâmina com tricomas, 0,15-0,30 $\mathrm{mm}$ compr., catenados; indúsio presente, com tricomas catenados nas margens.

Material examinado: 20-X-1958, M. Kuhlmann s.n. (SP154340).

Distribuição geográfica: Guiana e Brasil (Paraíba, Amazonas, Minas Gerais, Rio de Janeiro, São Paulo, Paraná e Santa Catarina).

O espécime estudado enquadra-se na variação morfológica de Ctenitis falciculata segundo o conceito utilizado por Christensen (1913).

Essa espécie é caracterizada pela presença de escamas lanceoladas, geralmente castanhoescuras, com margens denticuladas sobre a costa abaxialmente; costa e nervuras adaxialmente sem tricomas glandulares, porém com tricomas catenados.

Ctenitis aspidioides é a espécie mais semelhante e que também ocorre no PEFI, porém difere pela presença de tricomas catenados 0,05-0,10 $\mathrm{mm}$ compr. nas margens da lâmina e 0,1-0,2 mm compr. sobre a costa adaxialmente, bem como pela presença de escamas lineares abaxialmente sobre a costa e cóstula.

Segundo Christensen (1913), dentre as espécies com pinas com incisões $1 / 3 \mathrm{a}^{2 / 3}$ da distância entre a margem e a costa, a mais semelhante a C. falciculata é Ctenitis pedicellata (Christ) Copel., no entanto difere por não apresentar indúsio e possuir 4-5 nervuras por segmento chegando próximas ao sinus.

\section{Lastreopsis Ching}

Plantas terrestres ou raramente epífitas. Rizoma curto a longo-reptante ou subereto, com escamas. Lâmina (2-)3-5-pinada, catadrômica ou anadrômica, cartácea a levemente coriácea; pinas proximais mais desenvolvidas basiscopicamente (em muitas espécies); raque com duas bordas proeminentes na face adaxial, contínuas com a raquíola e costa, costa alada; indumento presente formado por tricomas glandulares adpressos abaxialmente no tecido laminar ou ausentes e tricomas clavados sobre a raque e a raquíola, escamas ausentes ou presentes; gemas presentes, próximas ao ápice da raque ou costa, ou ausentes; nervuras livres, visíveis ou inconspícuas em ambas as superfícies laminares, livres, simples ou furcadas, com ápice delgado (não claviforme) terminando antes das margens da lâmina, nervura proximal do lado basiscópico das pínulas distais originando-se da cóstula. Soros com ou sem indúsio, indúsio quando presente arredondado-reniforme; esporângios com tricomas glandulares no pedicelo ou tricomas ausentes.

É um gênero pantropical com cerca de 36 espécies, encontradas nas florestas tropicais e temperadas, das quais 5-6 ocorrem na América Central e na América do Sul (Mickel \& Smith 2004b).

Lastreopsis amplissima (C. Presl) Tindale, Victoria Naturalist 73: 185. $1957 \equiv$ Polystichum amplissimum C. Presl, Tent. Pterid.: 84. 1836.

Frondes (0,7-)1,8-2,4 m compr.; escamas da 


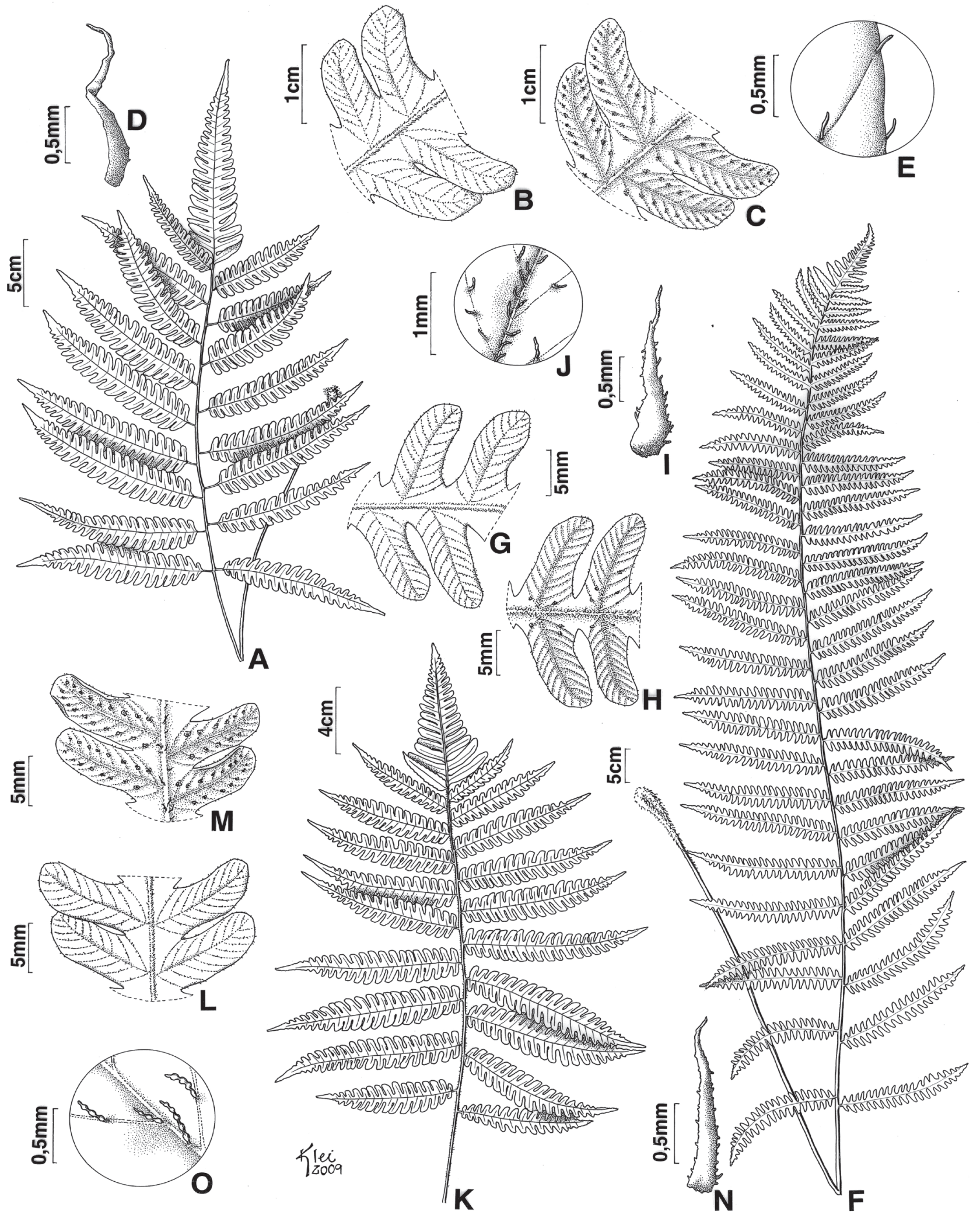

Figura 1 A-E. Ctenitis aspidioides (Prado 1442). A. Aspecto geral da fronde. B. Superfície adaxial da pina. C. Superfície abaxial da pina. D. Escama da costa. E. Detalhe da margem da lâmina com tricomas. F-J. Ctenitis distans (Handro 2213). F. Aspecto geral da fronde. G. Superfície adaxial da pina. H. Superfície abaxial da pina. I. Escama da costa. J. Detalhe dos tricomas sobre as nervuras, face adaxial da lâmina. K-O. Ctenitis falciculata (Kuhlmann s.n., SPF154340). K. Aspecto geral de parte de uma fronde. L. Superfície adaxial da pina. M. Superfície abaxial da pina. N. Escama da costa. O. Detalhe dos tricomas sobre as nervuras, face adaxial da lâmina.

Figure 1 A-E. Ctenitis aspidioides (Prado 1442). A. General aspect of a frond. B. Adaxial pinna surface. C. Abaxial pinna surface. D. Scale from costa. E. Detail of the lamina margin with hairs. F-J. Ctenitis distans (Handro 2213). F. General aspect of a frond. G. Adaxial pinna surface. H. Abaxial pinna surface. I. Scale from costa. J. Detail of the hairs on the veins on the adaxial lamina surface. K-O. Ctenitis falciculata (Kuhlmann s.n., SPF154340). K. General aspect of part of a frond. L. Adaxial pinna surface. M. Abaxial pinna surface. N. Scale from costa. O. Detail of the hairs on the veins on the adaxial lamina surface. 
base do pecíolo 3,0-6,0 × 0,7-1,0 mm, lineares a lanceoladas, margens inteiras, levemente ciliadas na base, castanho-escuras, quase negras, não formando um tufo denso; lâmina (0,3-)1,0-1,3 m compr., 3-5-pinado-pinatissecta na base, 3-pinadopinatissecta medianamente; pinas pecioluladas, peciólulo (2,0-)6,0-6,5 cm compr., pina proximal (20)45-63 cm compr., fortemente inequilateral; pínulas acroscópicas não reduzidas em direção à base da pina; raquíola abaxialmente sem tricomas, com escamas 1,0-3,5 mm compr., não buladas, linearlanceoladas, margens denticuladas, castanho-claras a castanho-escuras, adaxialmente densamente revestida de tricomas ca. $0,1 \mathrm{~mm}$ compr., clavados, sem escamas; cóstula abaxialmente sem tricomas, com escamas semelhantes às da raquíola, adaxialmente com tricomas clavados semelhantes às da raquíola, sem escamas; tecido laminar entre as nervuras abaxialmente sem tricomas, com escamas unisseriadas esparsas, filiformes, adpressas, ca. 0,2(-0,3) $\mathrm{mm}$ compr., castanho-avermelhadas, adaxialmente sem tricomas e escamas; nervuras inconspícuas em ambas as superfícies laminares, abaxialmente sem tricomas, escamas unisseriadas esparsas, adaxialmente sem tricomas e escamas; margens da lâmina inteiras; indúsio presente, margens sem tricomas.

Material examinado: 5-IX-1932, F.C. Hoehne s.n. (SP30028); 13-VII-1960, G. Eiten et al. 2085 (SP); 25-IV-1973, O. Handro 2222 (SPF); 6-X-2003, J. Prado \& D.M. Vital 1438 (SP); 5-II-2004, J. Prado 1459 (SP); 20-XII-2005, J. Prado \& G.B. Silva 1620 (SP); 10-II-2009, J. Prado \& R. Y. Hirai 2021 (SP). Distribuição geográfica: Venezuela, Guiana, Bolívia, Paraguai, Argentina e Brasil (Rio de Janeiro, São Paulo, Paraná, Rio Grande do Sul e Santa Catarina).
Esta espécie é facilmente reconhecida pela presença de pinas anadrômicas (a primeira pínula da pina origina-se do lado acroscópico) e ausência de gemas sobre a raque.

Além de Lastreopsis amplissima, ocorrem no Brasil duas outras espécies: L. acuta (Hook.) Tindale e L. effusa (Sw.) Tindale que diferem pelas pinas catadrômicas, bem como pela presença de gemas sobre a raque na base das pinas distais.

\section{Megalastrum Holttum}

Plantas terrestres. Rizoma ereto a decumbente, com escamas. Lâmina 1-4-pinado-pinatífida, catadrômica, acima das pinas proximais; pina proximal inequilateral e mais desenvolvida do lado basiscópico ou raramente equilateral; raque, costa e cóstula não sulcadas ou levemente sulcadas adaxialmente, com escamas e tricomas, densamente pubescentes sobre a superfície adaxial, indumento formado por tricomas aciculares esbranquiçados, antrorsamente estrigosos, multicelulares ou tricomas glandulares, arredondados, brilhantes, amarelados a alaranjados, sésseis a pedicelados, segmento proximal do lado basiscópico das pínulas distais, decorrente e adnado à raque; nervuras dos segmentos originando-se da raquíola; ápice das nervuras claviforme, hidatódios presentes, visíveis adaxialmente na lâmina; indúsio ausente ou raramente presente, circular, castanho, rígido, em algumas espécies reduzido e inconspícuo.

É um gênero quase que exclusivamente Neotropical, ocorrendo desde o México e Cuba até o sul do Chile. Somente três espécies ocorrem no Velho Mundo (África, Ilhas Comores, Reunião e Madagascar) (Moran et al. 2009).

\section{Chave para as espécies de Megalastrum}

1. Indúsio presente, persistente; cóstula abaxialmente com escamas buladas; tricomas glandulares presentes no tecido laminar entre as nervuras adaxialmente M. crenulans

1. Indúsio ausente; cóstula abaxialmente com escamas unisseriadas; tricomas glandulares ausentes no tecido laminar entre as nervuras adaxialmente

2. Lâmina 2-pinado-pinatissecta na base; tecido laminar entre as nervuras abaxialmente e adaxialmente com tricomas aciculares esparsos M. albidum

2. Lâmina 3-pinado-pinatífida na base; tecido laminar entre as nervuras abaxialmente e adaxialmente sem tricomas M. connexum

Megalastrum albidum R.C. Moran, J. Prado \& Labiak, Amer. Fern J. 89: 10. fig. 9E-H. 2009.
Frondes ca. 1,3 m compr.; escamas da base do pecíolo 1,2-2,2 $\mathrm{cm} \times 0,1-0,4 \mathrm{~mm}$, lineares, 
esparsamente denticuladas, castanho-claras, geralmente planas, formando um tufo denso; lâmina ca. $83 \mathrm{~cm}$ compr., 2-pinado-pinatissecta na base, 2-pinado-pinatífida medianamente; pinas pecioluladas, peciólulo 1,7-1,8 cm compr., pina proximal ca. $34 \mathrm{~cm}$ compr., fortemente inequilateral; pínulas acroscópicas levemente reduzidas em direção à base da pina; raquíola abaxialmente sem tricomas ou estes raramente presentes, com escamas esparsas, 1,0-2,5 mm compr., não buladas, lineares, margens denticuladas, adaxialmente densamente revestido de tricomas 0,3-1,0 $\mathrm{mm}$ compr., aciculares, sem tricomas glandulares e escamas; cóstula abaxialmente com tricomas 0,3-0,7 mm compr., sem tricomas glandulares, com escamas unisseriadas esparsas, filiformes, adpressas, ca. 0,1 mm compr., castanhoavermelhadas, adaxialmente com tricomas 0,2-0,7 $\mathrm{mm}$ compr., aciculares, sem tricomas glandulares e escamas; tecido laminar entre as nervuras abaxialmente com tricomas esparsos, 0,2-0,5 mm compr., aciculares, sem tricomas glandulares, com escamas unisseriadas esparsas, adaxialmente com tricomas esparsos, 0,2-0,6 mm compr., aciculares, sem tricomas glandulares e escamas; nervuras visíveis em ambas as superfícies laminares, abaxialmente com tricomas 0,2-1,0 mm compr., aciculares, com escamas unisseriadas esparsas, adaxialmente com tricomas 0,2-0,8 mm compr., aciculares, sem tricomas glandulares e escamas; margens da lâmina ciliadas, cílios 0,2-0,3 mm compr.; indúsio ausente.

Material examinado: 20-XII-2005, J. Prado \& G.B. Silva 1616 (SP).

Distribuição geográfica: Sudeste e Sul do Brasil (São Paulo e Paraná).

Megalastrum albidum pode ser reconhecida pela presença de tricomas aciculares esparsos sobre o tecido laminar entre as nervuras abaxialmente e adaxialmente.

O espécime do PEFI difere um pouco daqueles descritos por Moran et al. (2009) por também apresentar tricomas menores $(0,2-0,6 \mathrm{~mm}$ compr. vs. 0,4-0,6 mm compr.) entre as nervuras adaxialmente, no entanto em relação às demais características diagnósticas da espécie, o material do PEFI é inteiramente similar.

A espécie mais semelhante é Megalastrum canescens (Kunze ex Mett.) A.R. Sm. \& R.C. Moran, mas difere por apresentar tricomas glandulares no tecido laminar entre as nervuras abaxialmente. Também pode ser confundida com M. brevipubens R.C. Moran et al. por ambas possuírem tricomas aciculares no tecido laminar entre as nervuras abaxialmente. Porém, esta última difere por apresentar tricomas aciculares no tecido laminar entre as nervuras abaxialmente com aproximadamente 0,1 mm compr. (vs. 0,4-0,6 mm compr.) (Moran et al. 2009).

Megalastrum connexum (Kaulf.) A.R. Sm. \& R.C. Moran, Amer. Fern J. 77: 128. 1987 EPolypodium connexum Kaulf., Enum. Filic.: 120. 1824.

Frondes ca. 2,0 m compr.; escamas da base do pecíolo 1,7-2,5 $\mathrm{cm} \times 0,3-1,0 \mathrm{~mm}$, lineares a levemente lanceoladas, esparsamente denticuladas, castanho-claras, levemente espiraladas a crispadas, formando um tufo denso; lâmina ca. 1,2 m compr., 3-pinado-pinatífida na base, 2-pinado-pinatífida medianamente; pinas pecioluladas, peciólulo 1,7$1,9 \mathrm{~cm}$ compr.; pina proximal ca. $40 \mathrm{~cm}$ compr., fortemente inequilateral; pínulas acroscópicas levemente reduzidas em direção à base da pina; raquíola abaxialmente sem tricomas, com escamas esparsas, 2,0-3,0 mm compr., não buladas, lineares, adaxialmente densamente revestida de tricomas 0,20,4 mm compr., aciculares, levemente acastanhados, principalmente nas paredes transversais, sem tricomas glandulares e escamas; cóstula abaxialmente com tricomas esparsos, 0,20-0,25 mm compr., aciculares, sem tricomas glandulares, com escamas unisseriadas esparsas, filiformes, adpressas, ca. 0,1 $\mathrm{mm}$ compr., castanho-avermelhadas, adaxialmente com tricomas 0,3-0,4 mm compr., aciculares, sem tricomas glandulares e escamas; tecido laminar entre as nervuras abaxialmente sem tricomas, com escamas unisseriadas esparsas, adaxialmente sem tricomas e escamas; nervuras visíveis em ambas as superfícies laminares, abaxialmente com tricomas esparsos, ca. 0,2 $\mathrm{mm}$ compr., aciculares, escamas unisseriadas esparsas, adaxialmente sem tricomas e escamas; margens da lâmina esparsamente ciliadas ou sem cílios, cílios quando presentes ca. $0,1 \mathrm{~mm}$ compr.; indúsio ausente.

Material examinado: 3-I-1972, O. Handro 2193 (SP); 1-VIII-2008, J. Prado \& R.Y. Hirai 2005 (NY, SP, UPCB).

Distribuição geográfica: Argentina, Paraguai, Uruguai e Brasil (Bahia, Espírito Santo, Minas Gerais, Rio de Janeiro, São Paulo, Paraná, Santa Catarina e Rio Grande do Sul).

Esta espécie é caracterizada por apresentar raquíola sem tricomas abaxialmente e pela presença de escamas unisseriadas na cóstula e nervuras 
abaxialmente. Ambas as superfícies da lâmina entre as nervuras não possuem tricomas aciculares nem glandulares, apenas algumas escamas unisseriadas podem ser observadas abaxialmente.

Os espécimes analisados apresentam raquíola adaxialmente com tricomas, porém esses são levemente castanhos e podem ser confundidos com as escamas unisseriadas ("proscales"). No entanto, os tricomas são robustos, eretos a estrigosos, enquanto que as escamas geralmente são adpressas e delicadas. Além disso, a observação dessas escamas unisseriadas é dificultada por essa coloração semelhante à dos tricomas.

A espécie mais semelhante é Megalastrum brevipubens pela forma da lâmina 3-pinado-pinatífida na base e 2-pinado-pinatífida medianamente, mas difere por apresentar tricomas aciculares no tecido laminar entre as nervuras abaxialmente (Moran et al. 2009).

Megalastrum crenulans (Fée) A.R. Sm. \& R.C. Moran, Amer. Fern J. 77: 127. $1987 \equiv$ Aspidium crenulans Fée, Crypt. Vasc. Brésil 1: 139, tab. 47, fig. 1. 1869.

Frondes ca. 1,5 m compr.; escamas da base do pecíolo ca. $2,0 \mathrm{~cm} \times 0,1 \mathrm{~mm}$, lineares, esparsamente denticuladas, castanho-claras, levemente espiraladas a crispadas, formando um tufo denso; lâmina ca. 70 cm compr., 4-pinado-pinatífida na base, 3-pinadopinatífida medianamente; pinas pecioluladas, peciólulo até 1,5 cm compr.; pina proximal 37-43 cm compr., conspicuamente inequilateral; pínulas acroscópicas levemente reduzidas em direção à base da pina; raquíola abaxialmente com tricomas $0,5-0,8$ $\mathrm{mm}$ compr., aciculares, com tricomas glandulares 0,05-0,10 mm compr., com escamas 1,1-2,7 mm compr., não buladas, lanceoladas, subinteiras, adaxialmente densamente revestido de tricomas 0,3$0,9 \mathrm{~mm}$ compr., aciculares, sem tricomas glandulares e escamas; cóstula abaxialmente com tricomas $0,3-$ $0,5 \mathrm{~mm}$ compr., aciculares, com tricomas glandulares, 0,05-0,10 mm compr., com escamas ca. 1,0-1,4 mm compr., buladas, subinteiras, adaxialmente com tricomas $0,4-0,8 \mathrm{~mm}$ compr., aciculares, raramente com tricomas glandulares, ca. 0,05 $\mathrm{mm}$ compr., sem escamas; tecido laminar entre as nervuras abaxialmente densamente revestido de tricomas 0,1 $0,2 \mathrm{~mm}$ compr., aciculares, sem tricomas glandulares ou, raramente estes presentes e inconspícuos, com escamas unisseriadas esparsas, filiformes, adpressas, ca. $0,1 \mathrm{~mm}$ compr., castanho-avermelhadas, adaxialmente sem tricomas aciculares, com tricomas glandulares esparsos e conspícuos; nervuras visíveis em ambas as superfícies laminares, abaxialmente com tricomas 0,1-0,2 mm compr., aciculares, raramente com tricomas glandulares, escamas unisseriadas esparsas, adaxialmente com tricomas esparsos, 0,2$0,4 \mathrm{~mm}$ compr., aciculares, sem tricomas glandulares e escamas; margens da lâmina densamente ciliadas, cílios 0,2-0,3 mm compr.; indúsio presente, circular, castanho-escuro.

Material examinado: 16-V-1973, O. Handro 2224 (GH, HB, SP, SPF, US).

Distribuição geográfica: Venezuela, Paraguai e Brasil (Minas Gerais, Paraná, Rio de Janeiro, Rio Grande do Sul e São Paulo).

Esta espécie é facilmente reconhecida dentre as que ocorrem no PEFI por apresentar indúsio, bem como pelos tricomas glandulares esparsos no tecido laminar entre as nervuras adaxialmente.

A espécie mais semelhante é Megalastrum indusiatum R.C. Moran et al., que também possui indúsio, porém reduzido, cobrindo apenas parcialmente o soro. O tamanho do indúsio é aproximadamente o tamanho da cápsula de um esporângio.

\section{Agradecimentos}

Ao CNPq pela concessão da Bolsa de Produtividade em Pesquisa e auxílio para este projeto (processo 300843-93-3).

\section{Literatura citada}

Boldrin, A.H.L. \& Prado, J. 2007. Pteridófitas terrestres e rupícolas do Forte dos Andradas, Guarujá, São Paulo, Brasil. Boletim de Botânica da Universidade de São Paulo 25: 1-69.

Christensen, C. 1913. A monograph of the genus Dryopteris. Part I. The tropical American pinnatifid-bipinnatifid species. Mémoires de 1'Académie Royale des Sciences et des Lettres de Danemark, Copenhague. $7^{\mathrm{a}}$ série, section dês Sciences, t. X, nㅡ 2 .

Fidalgo, O. \& Bononi, V.L.R. (coords.). 1984. Técnicas de coleta, preservação e herborização de material botânico. Manual 4. Instituto de Botânica, São Paulo.

Hoehne, F.C., Kuhlmann, M. \& Handro, O. 1941. O Jardim Botânico de São Paulo. Secretaria da Agricultura, Indústria e Comércio, Departamento de Botânica do Estado, São Paulo. 
Melhem, T.S., Giulietti, A.M., Forero, E., Barroso, G.M., Silvestre, M.S.F., Jung, S.L., Makino, H., Melo, M.M.R.F., Chiea, S.C., Wanderley, M.G.L., Kirizawa, M. \& Muniz, C. 1981. Planejamento para elaboração da "Flora Fanerogâmica da Reserva do Parque Estadual das Fontes do Ipiranga (São Paulo, Brasil)". Hoehnea 9: 63-74.

Mickel, J.T. \& Smith, A.R. 2004a. 30. Ctenitis. In: J.T. Mickel \& A.R. Smith (eds.). The Pteridophytes of Mexico. Memoirs of the New York Botanical Garden 88: 219-233.

Mickel, J.T. \& Smith, A.R. 2004b. 60. Lastreopsis. In: J.T. Mickel \& A.R. Smith (eds.). The Pteridophytes of Mexico. Memoirs of the New York Botanical Garden 88: 358-360.

Milanez, A.I., Bicudo, C.E.M., Vital, D.M. \& Grandi, R.A.P. 1990. Criptógamos do Parque Estadual das Fontes do Ipiranga, São Paulo, SP: Planejamento. Hoehnea 17: 43-49.

Moran, R.C. 1995. Tectariaceae. In: R.C. Moran \& R. Riba (eds.). Psilotaceae a Salviniaceae. In: G. Davidse, M.S. Sousa \& S. Knapp (eds.). Flora Mesoamericana. Universidade Nacional Autónoma de México, Ciudad de México, v. 1, pp. 195-470.

Moran, R.C., Prado, J. \& Labiak, P.H. 2009. Megalastrum (Dryopteridaceae) in Brazil, Paraguay, and Uruguay. American Fern Journal 99: 1-44.
Moran, R.C. \& Riba, R. 1995. Psilotaceae a Salviniaceae. In: G. Davidse, M.S. Sousa \& S. Knapp (eds.). Flora Mesoamericana. Universidade Nacional Autónoma de México, Ciudad de México, v. 1, pp. 1-470.

Pichi-Sermolli, R.E.G. 1996. Authors of scientific names in Pteridophyta. Royal Botanic Gardens, Kew.

Prado, J. 2004. Criptógamos do Parque Estadual das Fontes do Ipiranga, São Paulo, SP. Pteridophyta: chave para as famílias; 2 . Blechnaceae. Hoehnea 31: 1-10.

Rosenstock, E. 1915. Filices brasiliensis novae. Hedwigia 56: 355-371.

Salino, A. \& Morais, P.O. 2003. New combinations in the Tropical American Ctenitis (Tectariaceae). American Fern Journal 93: 32-35.

Smith, A.R., Pryer, K.M., Schuettpelz, E., Korall, P., Schneider, H. \& Wolf, P.G. 2006. A classification for extant ferns. Taxon 55: 705-731.

Smith, A.R., Pryer, K.M., Schuettpelz, E., Korall, P., Schneider, H. \& Wolf, P.G. 2008. Fern classification. In: T.A. Ranker \& C.H. Haufler (eds.). Biology and evolution of ferns and Lycophytes. Cambridge University Press, Cambridge, pp. 417-467.

Tindale, M. 1965. A monograph of the genus Lastreopsis Ching. Contributions from the New South Wales National Herbarium 3: 249-339, t. 9-23. 